\title{
PESAN SEMIOTIK PADA TRADISI MAKAN TABHEG DI PONDOK PESANTREN
}

\author{
Bambang Subahri \\ Institut Agama Islam Syarifuddin Lumajang \\ Email: bambang.subahri@gmail.com
}

\section{ABSTRACT}

Tabheg is one type of food wrapped in banana leaves filled with rice with very simple side dishes such as salted fish, eggplant, chili sauce and crackers as a complement. Tabheg is a souvenir brought by the guardians of students when visiting their children in the boarding school. The tradition of bringing this tabheg is often found in Islamic boarding schools in the East Java, area Tapal Kuda. The tradition of eating tabheg for santri is a sign (representamen) with the values of togetherness and simplicity (interpretant) that can be conveyed through the form of food (object) that is shared by the students without distinguishing economic background and social stratification of the family. Phenomenon in the tradition of eating tabheg is believed to have a rich meaning of symbolic messages which are full of philosophical meanings so as to form patterns of human behavior. Exposure analysis of the tradition of eating tabheg is a qualitative study with a literature study approach, departing from the perspective of communication science using the concept of Charles Sanders Pierce with his trichotomies and psychological studies that form the basis of behavior formation. In addition it also aims to explore the constructive meaning of the pesantren tradition which is a reference to the santri mindset to shape behavior. The results of the analysis based on semiotic messages on the tabheg eating tradition for students based on representamen, interpretants and objects produce a constructive concept of santri personality characterized by traditional Islam. Where the santri character is built from the meaning implied in symbolic messages in the form of togetherness and simplicity that is internalized in the form of peace-loving behavior as a pesantren modality in realizing world peace.

Keywords: Semiotics, Tradition, Islamic Boarding School, Tabheg

\section{PENDAHULUAN}

Tabheg adalah salah satu jenis makanan tradisional masyarakat pandalungan ${ }^{1}$ yang dibungkus daun pisang berisi nasi dengan lauk-pauk yang sangat sederhana seperti ikan asin, terong, sambal dan kerupuk. Pada dasarnya tabheg merupakan buah tangan yang dibawa oleh para wali santri pada waktu menjenguk putra-putrinya di pondok pesantren. Pada umumnya para wali santri berkunjung pada hari libur pesantren yaitu hari Jum'at, sehingga disetiap lantai latar asrama banyak digelar

\footnotetext{
${ }^{1}$ Masyarakat pandalungan adalah masyarakat hibrida akibat terjadinya percampuran dua budaya dominan yaitu budaya Jawa dan budaya Madura. lihat: Ayu Sutarto, "Sekilas tentang Masyarakat Pandalungan," Makalah disampaikan pada acara pembekalan Jelajah Budaya 2006 yang diselenggarakan oleh Balai Kajian Sejarah dan Nilai Tradisional Yogyakarta, tanggal 7-10 Agustus 2006.
} 
makan tabheg secara bersama-masa tanpa membedakan status ekonomi dan stratifikasi sosial background keluarga. ${ }^{2}$

Makan Tabheg seakan menjadi iconic pesantren dalam menunjukkan wajah kesederhanaan santri. Hal demikian ditunjukkan karena makan tabheg dilakukan di lantai hanya beralaskan daun pisang dan dimakan menggunakan tangan kosong. Bahkan pada tahun 2017 santri Ponpes Nurul Jadid Paiton Kabupaten Probolinggo, memecahkan rekor MURI dengan sajian tabheg terpanjang. ${ }^{3}$ Makan tabheg atau makan nasi dengan alas daun pisang oleh ribuan santri ini dilakukan dalam rangka memperingati Hari Santri Nasional (HSN). ${ }^{4}$

Hari libur kegiatan pesantren merupakan momentum di mana tabheg menjadi hal yang ditunggu-tunggu santri. Makan tabheg juga mengajarkan para santri untuk selalu hidup sederhana, legowo ${ }^{5}$ dan syukur atas nikmat duniawi dan rohani. ${ }^{6}$ Kesederhanaan adalah kekuatan dasar dalam karakter dan membantu untuk menemukan eksistensi diri para santri.?

Pendidikan karakter yang secara implisit dalam tradisi makan tabheg di pesantren-pesantren se Jawa Timur, juga tidak dapat dipandang sebelah mata, berbagai upaya telah dilakukan para pakar pendidikan dalam meningkatkan pendidikan karakter karena muatan pendidikan karakter secara psikologis mencakup

\footnotetext{
${ }^{2}$ Berdasarkan data observasi lapangan yang dilakukan di pondok pesantren Kyai Syarifuddin Wonorejo Lumajang pada hari Jum'at tanggal 06 Sepember 2019.

3 Sebanyak 12.297 santri Pondok Pesantren Nurul Jadid Paiton Probolinggo merayakan Hari Santri Nasional dengan makan bersama 1.025 porsi nasi tabheg. Nomor Rekor : 8165. Rekoris : 1). Pimpinan Wilayah Ikatan Pelajar Nahdlatul Ulama Jawa Timur, 2). Pondok Pesantren Nurul Jadid Paiton Probolinggo. Pelaksanaan : Lapangan Pondok Pesantren Nurul Jadid, Probolinggo, 22 Oktober 2017. Lihat lampiran dokumen foto 1 dan 2 , dikutip 11/09/2019 dari: Tim MURI. Sajian Tabheg Terpanjang. 07 November 2017. Dari: http://muri.org/sajian-nasi-tabheg-terbanyak/

${ }^{4}$ M Rofiq. Santri Nurul Jadid Pecahkan Rekor MURI Makan Tabheg. detikNews. Dikutip 11/09/2019 dari: https://news.detik.com/berita-jawa-timur/d-3694807/santri-nurul-jadid-pecahkan-rekor-muri-makan-tabhek

${ }^{5}$ Legowo adalah menerima kondisi yang terjadi sebagai ketetapan Tuhan. Dibutuhkan penjelasan panjang untuk menjabarkan satu kata saja. Tentu pelaksanaan legowo lebih mudah diucapkan daripada dilaksanakan. Tapi kalau bisa, maka segala perkara dan kejadian akan dianggap sebagai nikmat dan bukan kesusahan.

${ }^{6}$ Berdasarkan Data wawancara dengan Ustad Syamsul Arifin, salah seorang santri senior di Pondok Pesantren Kyai Syarifuddin Wonorejo Lumajang 12 Sepember 2019.

7 Mamarodi, R. S. (2015) dalam Cucu Arumsari. Konseling Individu dengan Teknik Modeling untuk Meningkatkan Kekuatan Karakter Kesederhanaan. Jurnal Konseling Indonesia. Vol. 4 No. 1, Oktober 2018. hlm. 1-15.
} 
dimensi moral reasoning, moral feeling dan moral behavior yang secara tidak langsung mendasari secara filosofis pada tradisi makan Tabheg oleh para santri. ${ }^{8}$

Lebih lanjut, komitmen nasional dalam menanamkan pendidikan karakter sangat sulit dibentuk tanpa menggunakan metode yang tepat, sehingga hal ini dituangkan dalam Undang-undang Nomor 20 Tahun 2003 tentang Sistem Pendidikan Nasional. Dalam Pasal 3. ${ }^{9}$ Dengan cara tidak sengaja pendidikan karakter di pesantren telah dierapkan secara non formal dan bersifat implisit sebagaimana kesederhanaan yang diaplikasikan dalam tradisi makan tabheg di pesantren-pesantren di Jawa Timur. Pembelajaran non formal yang telah menjadi tradisi ini telah memberikan banyak ruang bagi para santri untuk senantiasa menerapkan pendidikan karakter yang rumit dalam bentuk yang lebih sederhana.

Di samping kesederhanaan yang dapat diambil sebagai nilai pendidikan karakter pada tradisi makan tabheg. Kebersamaan juga menjadi bagian yang tak terpisahkan dalam tradisi ini. Kebersamaan dalam ranah yang lebih sempit dalam kajian psikologi disebut juga dengan istilah prososial. Perilaku prososial didefinisikan sebagai tindakan sukarela yang dimaksudkan untuk membantu atau memberi keuntungan pada individu atau sekelompok individu. ${ }^{10}$

Tradisi makan tabheg dalam kaitannya dengan sifat prososial santri dapat di tinjau dari sifat saling peduli satu sama lain. Sehingga hal ini tidak hanya besifat psikologis melainkan juga sosialis pada diri manusia yang saling membutuhkan satu sama lain. ${ }^{11}$ Karakter kebersamaan ini yang memberikan pembelajaran atau copyng behaviour santri dalam menanamkan sifat darmawan antar sesama yang tidak banyak dijumpai dilembaga-lemabaga pendidikan yang lain.

\footnotetext{
${ }^{8}$ H.A. Rodli Makmun. Pembentukan Karakter Berbasis Pendidikan Pesantren: Studi di Pondok Pesantren Tradisional dan Modern di Kabupaten Ponorogo. Cendekia. Vol. 12 No. 2, Juli - Desember 2014

9 Undang-undang Nomor 20 Tahun 2003 tentang Sistem Pendidikan Nasional Pasal 3:"Pendidikan nasional berfungsi mengembangkan kemampuan dan membentuk watak serta peradaban bangsa yang bermartabat dalam rangka mencerdaskan kehidupan bangsa, bertujuan untuk berkembangnya potensi peserta didik agar menjadi manusia yang beriman dan bertakwa kepada Tuhan Yang Maha Esa, berakhlak mulia, sehat, berilmu, cakap, kreatif, mandiri, dan menjadi warga negara yang demokratis serta bertanggung jawab".

${ }^{10}$ Perilaku prososial ini menunjuk pada respon yang nampak dan perilaku prososial yang manifest, bukan pada pengetahuan tentang norma sosial, motif, konsep-konsep moral, dan penalaran moral santri berkaitan dengan perilaku prososial. Lihat: Eisenberg, N. \& Mussen, P.H., 1989, The Roots of Prosocial Behavior in Children, New York : Cambridge University Press.

11 Septiana Dwiputri Maharani. Manusia sebahgai Homo Economicus: Refleksi Atas Kasus-kasus Kejahatan di Iindonesia. Jurnal Filsafat, Vol. 26, No. 1, Februari 2016.
} 
Kebersamaan yang merupakan proses berkembangnya ikatan emosional secara timbal balik antar individu bermanfaat untuk selalu menumbuhkan rasa percaya diri, dapat membina hubungan yang hangat, serta dapat menumbuhkan kemampuan intelektual dan psikologis. ${ }^{12}$ Dari dua dasar sifat kesederhanaan dan sifat kebersamaan inilah yang kerap disanjung-sanjung oleh berbagai pengamat politik dan para peneliti bahwa Indonesia memiliki potensi dalam penjadi public figure perdamaian karena tradisi-tradisi yang telah terbangun sejak dini oleh para penerus bangsa dalam hal ini generasi santri milenial.

\section{PERMASALAHAN}

Berdasarkan latar belakang ini, penulis bermaksud untuk mengkaji dan menganalisa makna pesan semiotik tradisi makan tabheg di pesantren-pesantren yang kerap di jumpai di daerah Tapal Kuda Jawa Timur, guna mendapatkan makna filosofi yang tersirat sehingga membentuk pola perilaku dan tindakan yang berulang (pattern behaviour).

\section{METODE}

Riset ini memakai metode kualitatif dengan pendekatan kajian literatur atau studi pustaka ${ }^{13}$. Teknik yang dilakukan adalah melakukan observasi atau pengamatan di lapangan. Kemudian, menganalisisnya dengan literatur-literatur yang berhubungan dengan fenomena tradisi di pesantren, maupun teori semiotik yang menjadi dasar pembahasan dari penelitian ini.

\section{PEMBAHASAN}

\section{Pesan Semiotik Charles Sanders Pierce}

Charles S. Pierce mengartikan ilmu semiotika sebagai "doktrin formal tentang tanda-tanda" (the formal doctrine of signs), sementara definisi lain mengatakan ilmu umum tentang tanda, "suatu ilmu yang mengkaji kehidupan

${ }^{12}$ Sofie Dkk. Designing Mom and Baby SPA Centre in Bekasi as Means of Optimizing the Togethernes Moment Between Mom and Baby. e-Proceeding of Art \& Design. Vol.2, No.2 Agustus 2015. ISSN : 2355-9349.

${ }^{13}$ Zed, M. (2008). Metode Penelitian Kepustakaan. Jakarta: Yayasan Pustaka Obor Indonesia. 
tanda-tanda di dalam masyarakat" (a science that studies the life if signs within society). Dengan demikian, bagi Pierce semiotika adalah suatu cabang dari filsafat yang bertujuan menggali makna dari sebuah simbol. ${ }^{14}$

Charles Sanders Pierce mengemukakan bahwa tanda "is something which stands to somebody for something in some respect or capacity". Sesuatu yang digunakan agar tanda bisa berfungsi oleh Pierce disebut ground. Konsekuensinya, tanda (sign atau representamen) selalu berada dalam hubungan triadik, yakni representament, object dan interpretan. ${ }^{15}$

Charles Sanders Pierce dikenal dengan konsep triadic atau konsep trikotomi yang terdiri atas: ${ }^{16}$ 1). Representamen: Sesuatu yang berfungsi sebagai tanda. 2). Object: sesuatu yang merujuk pada tanda. Object: dapat berupa representasi mental (ada dalam pikiran), dapat juga berupa sesuatu yang nyata di luar tanda. Dan 3). Interpretant: sesuatu yang merujuk pada makna dari tanda. ${ }^{17}$

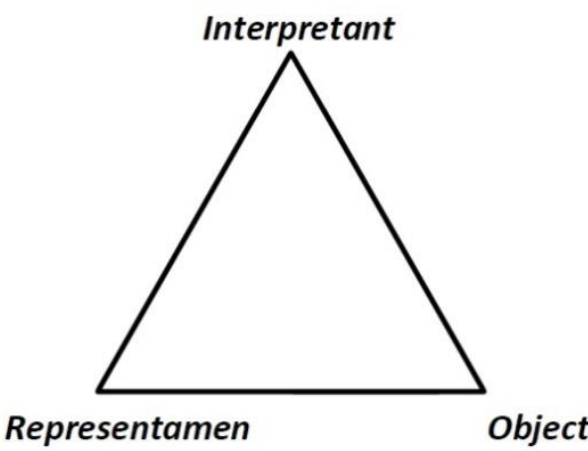

\section{Gambar. 1. Konsep Triadic Charles S. Pierce ${ }^{18}$}

Titik sentral dari teori semiotika Charles Sanders Pierce adalah sebuah trikotomi yang terdiri atas 3 tingkat dan 9 sub tipe tanda, sebagaimana tabel di bawah ini:

14 Kata "semiotika" berasal dari bahasa Yunani, semeion yang berarti "tanda" atau seme, yang berarti "penafsir tanda" Semiotika berakar dari studi klasik dan skolastik atas seni logika, retorika, dan poetika. Semiotika pada dasarnya merupakan studi atas kode-kode, yaitu sistem apapun yang memungkinkan seorang memandang entitas-entitas tertentu sebagai tanda-tanda atau sebagai sesuatu yang bermakna. Lihat: Alex Sobur, Semiotika Komunikasi, (Bandung: PT Remaja Rosdakarya, 2009). 16. Lihat juga: Kris Budiman, Semiotika Visual, (Yogyakarta: Jalasutra, 2011). 3.

15 Alex Sobur. 2016. Semiotika Komunikasi. (Bandung: Remaja Rosdakarya). 41. Lihat juga: Marcel Danesi 2010, Pengantar Memahami Semiotika Media, (Yogyakarta: Jalasutra). 22.

${ }^{16}$ Vera, Nawiroh, 2014. Semiotika dalam Riset Komunikasi, (Bogor: Ghalia Indonesia). 20.

${ }^{17}$ Kris Budiman, Semiotika Visual Konsep, Isu dan Problem Ikonisitas. (Yogyakarta: Jalasutra, 2011 ), 17.

${ }^{18}$ Budiman, Kris. 2005. Semiotika Visual. (Yogyakarta: Penerbit Buku Baik), 26. 
Tabel.2. Trikotomi Charles Sanders Pierce ${ }^{19}$

\begin{tabular}{|l|l|l|l|}
\hline Trikotomi & 1 & 2 & 3 \\
\hline Representamen & Qualisign & Sinsign & Legisign \\
\hline Object & Icon & Index & Symbol \\
\hline Interpretant & Rhema & Dicisign & Argument \\
\hline
\end{tabular}

Klasifikasi berdasarkan kategori yang dikembangkan oleh semiotika Pierce sebagaimana klasifikasi tingkaan berikut ini:

1. Firstness, yaitu suatu level yang masih bersifat kemungkinan atau potensial pada suatu tanda. Metode ini sebagaimana dapat dilihat adanya dan tidak adanya mengacu pada sesuatu yang lain, ini adalah kategori bebas dan langsung. Dalam tingkatan ini maka dalam trikotomi pertama, qualisign adalah sebagai kategori firstness. Lalu pada trikotomi kedua, icon adalah kategori firstness dan rhema adalah metode firstnes untuk trikotomi ketiga.

2. Secondness, yaitu merupakan level kedua yang bermakna faktual pada suatu tanda, sebuah metode yang menyangkut relasi antara yang pertama dengan yang kedua, ini merupakan kategori perbandingan, faktisitas, realitas, tindakan dan pengalaman dalam ruang dan waktu.

3. Thirdness, yaitu merupakan level ketiga yang bermakna formal atau sebuah tanda yang sudah memiliki aturan tertentu. Hal ini bermaksud mengantar yang kedua dalam hubungannya dengan yang ketiga. Ini adalah kategori mediasi kebiasaan, ingatan, kontinuitas, sintesis, komunikasi (semiosis) representasi dan tandatanda. ${ }^{20}$

Trikotomi pertama adalah representamen yang menjawab pertanyaan bagaimana hubungan tanda dengan dirinya yang terdiri atas:

1. Qualisign, adalah tanda yang berdasar pada sifat, misalnya kata-kata lemahlembut, merdu, kasar dan keras.

${ }^{19}$ Deledalle dalam Vera, Nawiroh 2014. Semiotika dalam Riset Komunikasi. (Bogor. Ghalia Indonesia). 23.

${ }^{20}$ Vera, Nawiroh M.Si. 2014. Semiotika dalam Riset Komunikasi. (Bogor. Ghalia Indonesia), 23. 
2. Sinsign, adalah tanda berdasarkan fakta atau eksistensi aktual benda pada peristiwa yang ada misalnya kata kabur atau keruh yang ada pada urutan kata "air sungai keruh yang menandakan bahwa ada hujan di hulu sungai".

3. Legisign adalah tanda yang didasari pada suatu aturan. Menjadi tanda berdasarkan suatu kesepakatan yang berlaku umum ataupun suatu kode. Misal rambu-rambu lalu lintas yang menandakan hal-hal yang boleh dan tidak boleh dilakukan manusia.

Trikotomi kedua, yaitu berdasarkan hubungan dengan objeknya, tanda diklasifikasikan menjadi:

1. Ikon, adalah tanda yang memiliki arti kemiripan. Mengandung rupa mudah dikenali oleh para pemakainya. Di dalam ikon hubungan antara representamen dan obyeknya terwujud sebagai kesamaan dalam beberapa kualitas.

2. Indeks, yaitu tanda yang memiliki arti kedekatan, keterkaitan dan fenomena atau eksistensial di antara representamen dan obyeknya. Di dalam indeks hubungan antara tanda dengan obyeknya bersifat konkrit, aktual dan biasanya melalui suatu cara yang sekuensial atau kausal, misalnya asap dengan api dan seterusnya.

3. Simbol, adalah suatu tanda yang memiliki makna kesepakatan atau aturan, dimana hubungan tanda dan denotasinya ditentukan oleh suatu peraturan yang bersifat umum atau suatu kesepakatan bersama.

Trikotomi ketiga, berdasarkan interpretannya dibagi menjadi:

1. Rhema, adalah suatu tanda yang memiliki makna kemungkinan, bilamana lambang tersebut interpretannya adalah sebuah first dan makna tanda tersebut masih dapat dikembangkan.

2. Decisign, adalah suatu tanda yang memiliki makna yang bisa disebut faktual. Apabila antara lambang dan interpretasinya terdapat hubungan yang benar ada (merupakan secondness).

3. Argument, adalah suatu tanda yang memiliki makna berlaku umum. Apabila suatu tanda dan interpretannya mempunyai sifat yang berlaku secara umum (merupakan thirdness).

Skema di atas ini menghasilkan rangkaian hubungan yang tak berkesudahan, maka gilirannya sebuah interpretan akan menjadi representamen, 
menjadi interpretan kembali, menjadi representamen kembali dan seterusnya. Gerakan yang tak berujung-pangkal ini sebagai proses semiosis tanpa batas.

\section{Makna Pesan Semiotik pada Tradisi Makan Tabheg di Pondok Pesantren}

Menjenguk anak di Pondok Pesantren sudah menjadi kewajiban bagi para orang tua wali santri dalam proses mendidikan anak-anaknya di kancah pendidikan Islam. ${ }^{21}$ Terdapat tipe-tipe orang tua wali santri dalam mendidik anakanaknya di pesantren, ada yang menjenguk sepekan sekali, sebulan sekali bahkan tidak jarang yang menjenguk setahun sekali. ${ }^{22}$ Dalam tulisan ini penulis menganalisis orang tua yang menjenguk putra-putrinya diantara sepekan hingga sebulan sekali.

Klasifikasi ini mengindikasikan bahwa posisi rumah dengan pesantren tidak terlalu jauh, hingga memungkinkan para orang tua wali santri membawa makanan yang dalam tulisan ini disebut dengan tabheg. Sejenis makanan berat yang akan dinalisis menggunakan pesan semiotik untuk mengungkap nilai-nilai kearifan lokal hingga berdampak pada perilaku santri.

Klasifikasi model tingkatan dalam teori Pierce yang menggunakan tandatanda dalam gambar dapat dilihat dari jenis tanda yang digolongkan dalam semiotika di antaranya sebagaimana tabel jenis tanda pada tradisi makan tabheg dalam konsep Charles Sanders Pierce sebagai berikut: ${ }^{23}$

Tabel. 3. Jenis Tanda Tradisi Makan Tabheg pada Konsep

Charles Sanders Pierce

\begin{tabular}{|c|c|c|}
\hline Jenis & Hubungan & Object Tanda dalam Tradisi \\
Tanda & antar Tanda & Makan Tabheg \\
& dan Sumber & \\
\hline
\end{tabular}

${ }^{21}$ Dalam bahasa lokal masyarakat pandalungan disenbut dengan istilah ngirem, nyangoin dan nyongngok.

22 Berdasarkan data observasi di pondok pesantren Kyai Syarifuddin Wonorejo Lumajang pada hari Jum'at tanggal 06 Sepember 2019.

23 Indiwan Seto Wahyu Wibowo, 2013. Semiotika Komunikasi : Aplikasi Praktis Bagi Penelitian Dan Skripsi Komunikasi, (Jakarta: Mitra Wacana Media). 17-24. Lihat juga: Vera, Nawiroh. 2014. Semiotika dalam Riset Komunikasi. (Bogor. Ghalia Indonesia), 23. 


\begin{tabular}{|c|c|c|}
\hline & Acuannya & \\
\hline Ikon & $\begin{array}{l}\text { Tanda } \\
\text { dirancang } \\
\text { untuk } \\
\text { merepresent } \\
\text { asikan } \\
\text { sumber } \\
\text { acuan } \\
\text { melalui } \\
\text { simulasi atau } \\
\text { persamaan } \\
\text { (artinya, } \\
\text { sumber } \\
\text { acuan dapat } \\
\text { dilihat, } \\
\text { didengar dan } \\
\text { seterusnya } \\
\text { dalam ikon). }\end{array}$ & $\begin{array}{l}\text { Dalam konteks firstness } \\
\text { pada tradisi makan tabheg, } \\
\text { merupakan ikon dalam } \\
\text { jenis tanda yang menjadi } \\
\text { penanda pada tradisi } \\
\text { berkunjung di pondok } \\
\text { pesantren. }\end{array}$ \\
\hline Indeks & $\begin{array}{l}\text { Tanda } \\
\text { dirancang } \\
\text { untuk } \\
\text { mengindikasi } \\
\text { kan sumber } \\
\text { acuan atau } \\
\text { saling } \\
\text { menghubun } \\
\text { gkan sumber } \\
\text { acuan. }\end{array}$ & $\begin{array}{l}\text { Secondness dalam object } \\
\text { tanda pada tradisi makan } \\
\text { tabheg dapat dijelaskan } \\
\text { bahwa terdapat } \\
\text { keterkaitan antara } \\
\text { berkunjung dengan buah } \\
\text { tangan sebagai bentuk } \\
\text { bawaan yang dalam hal ini } \\
\text { disebut dengan tabheg. }\end{array}$ \\
\hline Simbol & $\begin{array}{l}\text { Tanda } \\
\text { dirancang } \\
\text { untuk }\end{array}$ & $\begin{array}{l}\text { Thirdness pada object } \\
\text { simbol tradisi makan } \\
\text { Tabheg dapat dijelaskan }\end{array}$ \\
\hline
\end{tabular}




\begin{tabular}{|l|l|l|}
\hline & menyandika & bahwa belum mencapai \\
$\mathrm{n}$ sumber & posisi yang ketiga ini \\
acuan & karena makanan belum \\
melalui & mencapai legislasi atau \\
& kesepakatan & tertulis. \\
& atau & \\
& persetujuan. & \\
\hline
\end{tabular}

Upaya klasifikasi yang dilakukan oleh Pierce terhadap tanda memiliki kekhasan meski tidak dibilang sederhana berupa tipe-tipe tanda menjadi: ikon (icon), indeks (index), dan simbol (symbol) yang didasarkan atas relasi di antara representamen dan objek tabheg. ${ }^{24}$

Charles Sanders Pierce dikenal dengan konsep triadic dan konsep trikotomi untuk dijadikan pisau analisis pada tradisi makan tabheg yang terdiri atas: ${ }^{25} 1$ ). Representamen: Sesuatu yang berfungsi sebagai tanda, pada penelitian ini dalam representamen adalah Tabheg itu sendiri. 2). Object: sesuatu yang merujuk pada tanda berupa sesuatu yang nyata di luar tanda. Dan 3). Interpretant : sesuatu yang merujuk pada makna dari tanda. ${ }^{26}$ Dalam hal ini merujuk pada anjuran dari Islam yaitu kebersamaan dalam kesederhanaan.

Relasi triadik dalam semiosis Charles S. Pierce ini saling berhubungan satu sama lain dalam Tradisi Makan tabheg sebagaimana gambar di bawah ini:

${ }^{24}$ Lihat juga: Vera, Nawiroh M.Si. 2014. Semiotika dalam Riset Komunikasi. (Bogor. Ghalia Indonesia) 24. Winfried Nööth. From Representation to Thirdness and Representamen to Medium: Evolution of Piercean Key Terms and Topics. Transactions of the Charles S. Pierce Society, Vol. 47, No. 4 (Fall 2011), pp. $445-481$.

${ }^{25}$ Vera, Nawiroh, 2014. Semiotika dalam Riset Komunikasi, Bogor: Ghalia Indonesia. 20.

${ }^{26}$ Kris Budiman, Semiotika Visual Konsep, Isu dan Problem Ikonisitas. (Yogyakarta: Jalasutra, 2011$), 17$. Lihat juga: Vera, Nawiroh M.Si. 2014. Semiotika dalam Riset Komunikasi. (Bogor. Ghalia Indonesia), 23. 


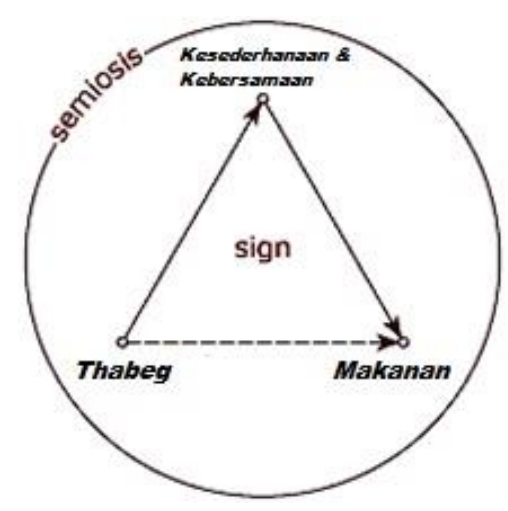

\section{Gambar. 2. Teori Relasi Triadik Charles S. Pierce Pada Tradisi Makan Tabheg di Pondok Pesantren ${ }^{27}$}

Teori dari Pierce sering kali disebut "grand theory" dalam semiotika karena gagasan Pierce bersifat menyeluruh, deskripsi struktural dari semua sistem penandaan pada tradisi makan tabheg. Pierce ingin mengidentifikasi partikel dasar dari tradisi makan tabheg dan menggabungkan kembali semua komponen dalam struktur tunggal. Sebuah tanda atau representamen memiliki arti sesuatu yang bagi seseorang mewakili sesuatu yang lain dalam beberapa hal atau kapasitas. Kebersamaan dalam kesederhanaan merupakan interpretant dari tanda yang pertama, pada gilirannya akan mengacu pada objek tertentu berupa makanan. Dengan demikian menurut Pierce, sebuah tanda atau representamen memiliki relasi “triadik" langsung dengan interpretan dan objeknya. Apa yang dimaksud dengan proses "semiosis" merupakan suatu proses yang memadukan entitas (berupa representamen) dengan entitas lain yang disebut objek. Proses ini oleh Pierce disebut sebagai signifikasi. ${ }^{28}$

Skema di atas ini menghasilkan rangkaian hubungan yang tak berkesudahan, maka gilirannya sebuah interpretan akan menjadi representamen, menjadi interpretan kembali, menjadi representamen kembali dan seterusnya. ${ }^{29}$ Gerakan yang tak berujung pangkal ini sebagai proses semiosis tanpa batas.

${ }^{27}$ Dalam memudahkan analisa pesan semiotik pada objek Tabheg lihat lampiran 3.

${ }^{28}$ Indiwan Seto Wahyu Wibowo, Semiotika Komunikasi : Aplikasi Praktis Bagi Penelitian Dan Skripsi Komunikasi, (Jakarta: Mitra Wacana Media, 2013), 17-24.

29 Winfried Nööth. From Representation to Thirdness and Representamen to Medium: Evolution of Piercean Key Terms and Topics. Transactions of the Charles S. Pierce Society, Vol. 47, No. 4 (Fall 2011), pp. 445-481 
Karena proses semiosis seperti tergambarkan pada skema di atas ini menghasilkan rangkaian hubungan yang tak berkesudahan, maka pada gilirannya sebuah interpretan akan menjadi representamen, menjadi interpretan lagi, menjadi representamen lagi, dan seterusnya. ${ }^{30}$

1. Tanda (representamen) adalah sesuatu yang berbentuk fisik yang ditangkap oleh panca indera manusia atau audiens dan merupakan sesuatu yang merujuk (merepresentasikan) hal yang lain di luar tanda itu sendiri. Acuan tanda ini disebut dengan objek.

2. Penggunaan tanda (interpretant), konsep pemikiran dua orang yang menggunakan tanda dan menurunkannya ke suatu makna tertentu atau makna lain yang berada dalam benak seseorang tentang objek yang dirujuk sebagai sebuah tanda.

3. Acuan tanda (object) adalah konteks sosial yang menjadi referensi dari sebuah tanda atau sesuatu yang dirujuk oleh tanda. ${ }^{31}$ Berdasarkan objeknya, Pierce membagi tanda atas icon (ikon), index (indeks), dan symbol (simbol). ${ }^{32}$

Titik sentral dari teori semiotika Charles Sanders Pierce adalah sebuah trikotomi yang terdiri atas 3 tingkat dan 9 sub tipe-tanda. Klasifikasi berdasarkan kategori yang dikembangkan oleh semiotika Pierce adalah:

Firstness, yaitu suatu level yang masih bersifat kemungkinan atau potensial pada suatu tanda. Secondness, yaitu merupakan level kedua yang bermakna faktual pada suatu tanda dan thirdness, yaitu merupakan level ketiga yang bermakna formal atau sudah memiliki aturan tertentu pada suatu tanda. ${ }^{33}$

Dengan pesan tanda di atas memicu pada perkembangan sebuah tradisi pesantren yang melingkupinya. Ini ditopang oleh kehadiran kiai sebagai penjaga keutuhan dan konsistensi pendiriannya dengan karakter yang dibentuk mulai

${ }^{30}$ Kris Budiman, Semiotika Visual Konsep, Isu, dan Problem Ikonisitas. (Yogyakarta: Jalasutra, 2011). 17-18. Lihat juga: Vera, Nawiroh M.Si. 2014. Semiotika dalam Riset Komunikasi. (Bogor. Ghalia Indonesia), 23.

${ }^{31}$ Rachmat Kriyantono, Teknik Praktis Riset Komunikasi, (Jakarta: Kencana, 2009). 265. Winfried Nööth. From Representation to Thirdness and Representamen to Medium: Evolution of Piercean Key Terms and Topics. Transactions of the Charles S. Pierce Society, Vol. 47, No. 4 (Fall 2011), pp. 445-481.

${ }^{32}$ Alex Sobur, Semiotika Komunikasi (Bandung: PT. Remaja Rosdakarya, 2009). 39. Lihat juga: Winfried Nööth. From Representation to Thirdness and Representamen to Medium: Evolution of Piercean Key Terms and Topics. Transactions of the Charles S. Pierce Society, Vol. 47, No. 4 (Fall 2011), pp. 445-481

${ }^{33}$ Vera, Nawiroh M.Si. 2014. Semiotika dalam Riset Komunikasi. (Bogor. Ghalia Indonesia), 23. 
dari hal yang kecil. ${ }^{34}$ Watak dan ideologi kiai menyatu dengan kelembagaan pesantren. Dengan misi utama menyebarluaskan ajaran agama secara internal dalam kalangan umat Islam.

Pesantren dengan berbagai bentuk pesan simbol yang menjadi tempat utama yang dijadikan sebagai rujukan untuk belajar keagamaan. Bahkan ketika nama Indonesia belum wujud. Pesantren berkembang sebagaimana perkembangan Indonesia sekaligus mendukung pemahaman keagamaan yang inklusif. Pada sisi tertentu, pesantren juga menjaga dan merawat tradisi masyarakat setempat. Sekaligus menjadi sebuah pendukung bagi keberlangsungan komunitas. 35

Tantangan pesantren adalah seiring dengan perkembangan modernitas, tentu tidak dapat melepaskan diri dari dinamika ini. Sebaliknya, pesantren justru dituntut untuk berbenah, mengadaptasi diri, dan melakukan sinergitas dengan segala dasar dan tradisi pesantren yang baik dan senantiasa relevan dengan kondisi sekarang. ${ }^{36}$

\section{PENUTUP}

Ada pun hasil analisis berdasarkan pesan semiotik pada tradisi makan tabheg bagi santri yang didasarkan pada representamen, interpretan dan object menghasilkan sebuah konsep konstruksi yang membentuk kepribadian santri berkarakter Islam tradisional. Representamen dalam konteks ini diindikasikan pada tabheg itu sendiri, objek pada bentuk makanan yang dibwa dan interpretan mengacu pada makna kebersamaan dan keserhanaan.

Karakter santri terbangun dari makna yang tersirat dalam pesan-pesan simbolik dari kebersamaan dan kesederhanaan (interpretan) yang terinternalisasikan dalam wijud perilaku cinta damai sebagai modalitas pesantren dalam mewujudkan perdamaian dunia. Sehingga kontruksi sosial yang dibangun dari kegiatan sehari-hari santri ini dapat menjadi bagian dari output perilaku dalam kepribadian dan karakter. 67.

${ }^{34}$ Zamakhsyari Dhofier, Tradisi Pesantren, Studi tentang Pandangan Hidup Kiai (Jakarta: LP3ES, 1990).

35 Uktambek Sultonov, "Waqf Administration in Tashkent prior to and After the Russian Conquest: A Focus on Rent Contracts for the Kulkedas Madrasa", Islam. Zeitschrift fur Geschichte und Kultur des Islamichen Orients, Vol. 88, No. 2 (2011), hlm. 324-351.

36 Amin Haedari, Masa Depan Pesantren Dalam Tantangan Modernitas dan Tantangan Kompleksitas Global (Jakarta: IRD Press, 2006). 89. 


\section{REFERENSI}

Budiman, Kris. 2011. Semiotika Visual Konsep, Isu dan Problem Ikonisitas. Yogyakarta: Jalasutra.

Dhofier, Zamakhsyari. 1990. Tradisi Pesantren, Studi tentang Pandangan Hidup Kiai. Jakarta: LP3ES.

Eisenberg, N. dan Mussen, P.H. 1989. The Roots of Prosocial Behavior in Children, New York: Cambridge University Press.

Haedari, Amin. 2006. Masa Depan Pesantren Dalam Tantangan Modernitas dan Tantangan Kompleksitas Global. Jakarta: IRD Press.

Indiwan Seto Wahyu Wibowo. 2013. Semiotika Komunikasi: Aplikasi Praktis Bagi Penelitian dan Skripsi Komunikasi, Jakarta: Mitra Wacana Media.

Kris, Budiman. 2011. Semiotika Visual, Yogyakarta: Jalasutra.

Kriyantono, Rachmat. 2009. Teknik Praktis Riset Komunikasi, Jakarta: Kencana.

Makmun H.A. Rodli. Pembentukan Karakter Berbasis Pendidikan Pesantren: Studi di Pondok Pesantren Tradisional dan Modern di Kabupaten Ponorogo. Cendekia. Vol. 12 No. 2, Juli - Desember 2014.

Mamarodi, R. S. (2015) dalam Cucu Arumsari. Konseling Individu dengan Teknik Modeling untuk Meningkatkan Kekuatan Karakter Kesederhanaan. Jurnal Konseling Indonesia. Vol. 4 No. 1, Oktober 2018.

Rofiq, M. Santri Nurul Jadid Pecahkan Rekor MURI Makan Tabheg. detikNews. Dikutip 11/09/2019 dari: https://news.detik.com/berita-jawa-timur/d-3694807/santri-nuruljadid-pecahkan-rekor-muri-makan-tabhek

Septiana, Dwiputri Maharani. Manusia sebahgai Homo Economicus: Refleksi Atas Kasuskasus Kejahatan di lindonesia. Jurnal Filsafat, Vol. 26, No. 1, Februari 2016.

Sofie Dkk. Designing Mom and Baby SPA Centre in Bekasi as Means of Optimizing the Togethernes Moment Between Mom and Baby. e-Proceeding of Art \& Design. Vol.2, No.2 Agustus 2015. ISSN : 2355-9349.

Sobur, Alex. 2009. Semiotika Komunikasi. Bandung: PT Remaja Rosdakarya. 
Sultonov, Uktambek. "Waqf Administration in Tashkent prior to and After the Russian Conquest: A Focus on Rent Contracts for the Kulkedas Madrasa", Islam-Zeitschrift fur Geschichte und Kultur des Islamichen Orients, Vol. 88, No. 2(2011).

Sutarto, Ayu. "Sekilas tentang Masyarakat Pandalungan," Makalah disampaikan pada acara pembekalan Jelajah Budaya 2006 yang diselenggarakan oleh Balai Kajian Sejarah dan Nilai Tradisional Yogyakarta, tanggal 7-10 Agustus 2006.

Tim MURI. Sajian Tabheg Terpanjang. 07 November 2017. Dari: http://muri.org/sajian-nasitabheg-terbanyak/

Vera, Nawiroh. 2014. Semiotika dalam Riset Komunikasi, Bogor: Ghalia Indonesia.

Winfried Nööth. From Representation to Thirdness and Representamen to Medium: Evolution of Piercean Key Terms and Topics. Transactions of the Charles S. Pierce Society, Vol. 47, No. 4 (Fall 2011), pp. 445-481

\section{LAMPIRAN-LAMPIRAN}

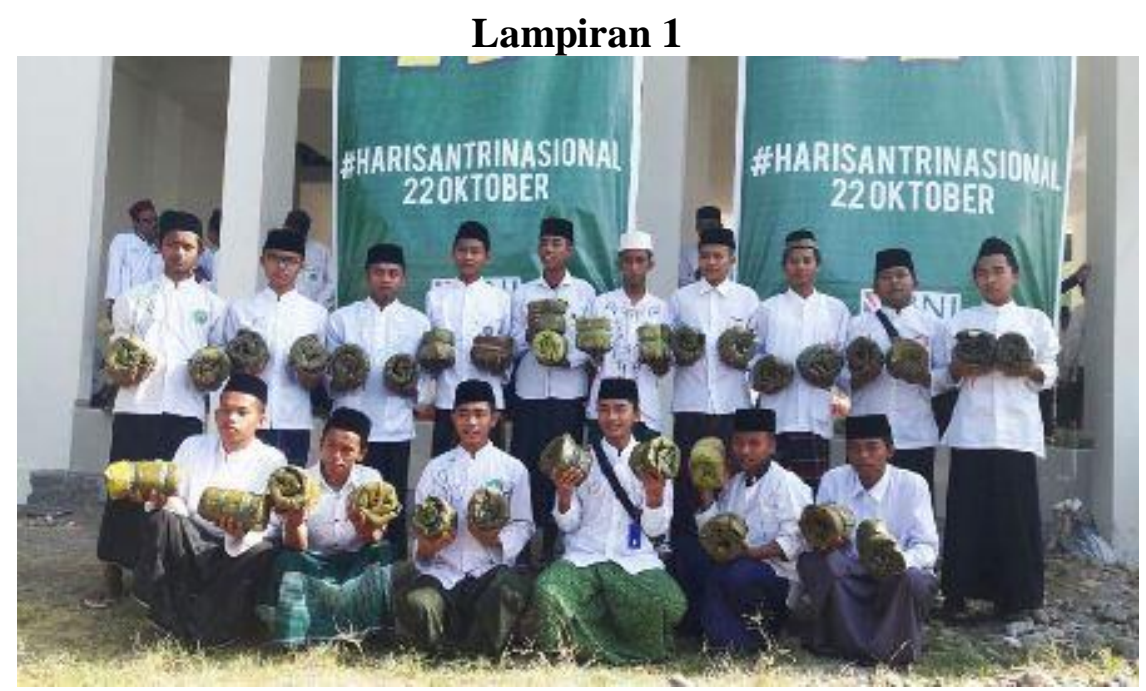




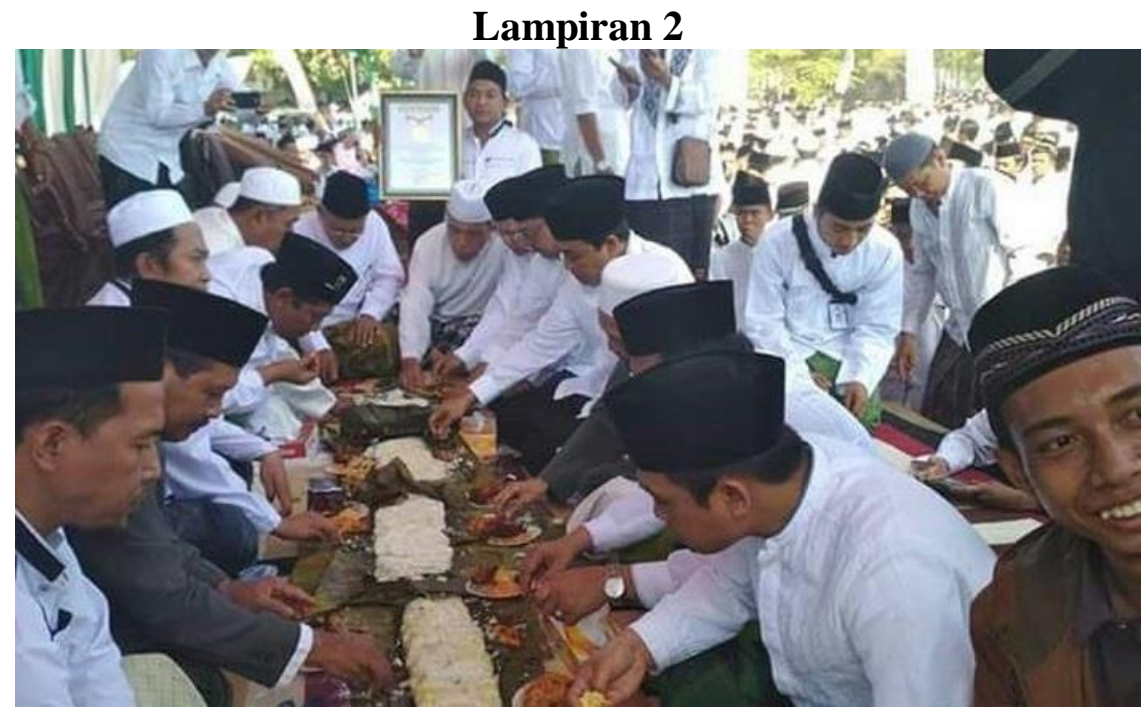

\section{Lampiran 3}

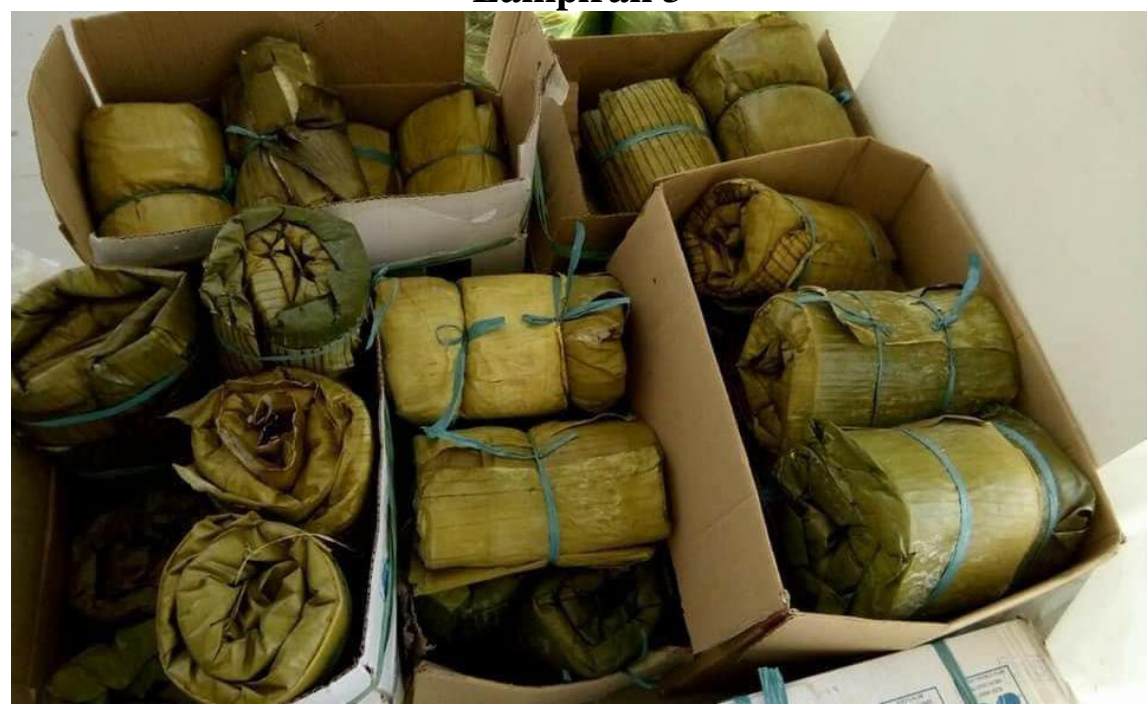

